\title{
Comentário sobre o artigo de Freitas et al.
}

Comment on the paper by Freitas

et al.

Comentario acerca del artículo de

Freitas et al.

http://dx.doi.org/10.1590/0102-311XC0010915

Maria do Carmo Leal

Escola Nacional de Saúde Pública Sergio Arouca, Fundação Oswaldo Cruz Rio de Janeiro, Brasil. ducaleal@gmail.com
Muito importante einteressante, no contexto atual do país, o artigo de Freitas et al. que se intitula O Parecer do Conselho Federal de Medicina, o Incentivo à Remuneração ao Parto e as Taxas de Cesariana no Brasil, cujo título me surpreendeu por não imaginar como poderiam ter realizado um estudo sobre este parecer e suas consequências sobre as taxas de cesariana no Brasil, dado que o referido parecer não foi referendado pela Agência Nacional de Saúde Suplementar (ANS), conforme nota no 394/2014/GEAS/GGRAS/DIPRO/ ANS, de 15 de maio de 2014.

Na verdade, os autores não examinaram exatamente essas relações nesse artigo, mas utilizaram a temática do parecer do Conselho Federal de Medicina (CFM) para notificar a sua insuficiência ou inadequação para reverter ou mesmo diminuir as taxas de cesarianas, dado que o maior risco para a ocorrência de uma cesariana é o atendimento ao parto ser realizado pelo mesmo médico que acompanhou a gestante durante o pré-natal. Nesse sentido, o parecer do CFM não contribuiria para reduzir o problema porque reforça o modelo atual de atenção ao parto que tem mantido um crescimento anual de dois pontos percentuais na taxa de cesariana.

Achados muito semelhantes ao desse estudo de Freitas et al. já haviam também sido encontrados por Torres 1 com dados da pesquisa Nascer no Brasil. A referida autora, em sua tese de doutorado, comparou os resultados alcançados por um hospital privado da Região Sudeste, que tinha um modelo atípico de atenção ao parto, com a amostra de hospitais privados da pesquisa na mesma região, que seguia o modelo atual de agendamento prévio das cesarianas, denominado de modelo de conveniência obstétrica. O hospital atípico caracterizava-se por oferecer uma atenção obstétrica centrada no trabalho de equipes formadas por médicos e enfermeiros obstétricos, tanto durante o pré-natal quanto no momento do parto, além de um diálogo permanente com as gestantes sobre as vantagens de um parto vaginal. Houve, portanto, uma quebra nessa relação de exclusividade da gestante com o seu pré-natalista, bem como foi introduzindo outro profissional, o enfermeiro obstétrico/obstetriz, no atendimento ao parto de baixo risco. Como consequência, as taxas de cesariana caíram à metade do observado nos hospitais privados que seguiam o modelo da conveniência obstétrica, com satisfação das usuárias e redução da internação em UTI neonatal.

A quase ausência de enfermeiros obstétricos/obstetrizes no atendimento ao pré-natal e parto também é outra característica própria do nosso modelo de atenção, embora não exclusiva do país. No Brasil, 93\% dos partos são realizados por médicos, e se considerarmos apenas os partos vaginais este valor atinge para $87 \%$ (dados não publicados da pesquisa Nascer no Brasil). Estudos mostram que midwives adequadamente qualificados têm um papel fundamental na promoção de um processo reprodutivo saudável, prestando um cuidado centrado na mulher e com um manejo racional e adequado dos recursos do sistema de saúde. Uma série do The Lancet denominada Midwifery recomenda esses profissionais como uma solução vital para promover uma atenção de alta qualidade para mães e crianças em todos os países 2 .

O modelo atual, que prioriza o agendamento prévio das cesarianas sem indicação clínica no setor privado, também é composto por outras características: a maioria desses hospitais não tem equipes de plantão e o corpo clínico é constituído predominantemente por médicos externos que possuem consultórios privados onde realizam o acompanhamento pré-natal. Dirigem-se aos hospitais com equipes próprias e externas ao hospital quando necessitam de internações por alguma complicação clínica das gestantes, ou para a realização do parto. Esses aspectos caracterizam também uma prática obstétrica isolada, completamente autônoma, ficando cada médico com a responsabilidade total sobre seus pacientes, sem compartilhamento de experiências e sem contar com uma organização que se responsabilize pelo estabelecimento de diretrizes clínicas, protocolos de atendimento e mesmo oferta de suporte para tomada de decisões.

Uma revisão sistemática 3 sobre intervenções não clínicas para a redução de cesarianas concluiu que há evidências de que se pode reduzir com segurança a prevalência de cesarianas nos casos de mulheres com cesariana anterior, quando se usa uma segunda opinião mandatória e de revisão por pares antes da indicação de cesarianas intraparto, vigilância da prevalência de cesarianas, adoção de estratégias que envolvam análise das práticas de profissionais de 
saúde e sejam baseadas em auditoria e feedback às equipes.

Dessa forma, para a redução das taxas de cesarianas no Brasil, as mudanças que precisam ser implantadas são complexas e em várias frentes. Devem ir para além do suporte financeiro a ser dado pela gestante ao seu obstetra para a criação da disponibilidade de tempo do médico para o acompanhamento do parto vaginal, conforme sugerido no parecer da CFM, muito bem contra argumentado pelos autores desse estudo e inclusive vetado pela ANS por constituir uma ilegalidade.

Foi uma pena que os autores não puderam analisar o pagamento à parte feito pelas mulheres com planos de saúde aos seus médicos, para avaliar o efeito isolado desta variável.

$\mathrm{O}$ artigo de Freitas et al. mostra claramente que ter o mesmo médico no pré-natal e no parto é uma variável mediadora do tipo de parto, mas, como estamos discutindo aqui, não é o fato de ser o mesmo médico em si que representa risco para a ocorrência de uma cesariana. Essa variável é, na verdade, uma proxy do modelo de assistência obstétrica que temos no país, e por isto tem poder para potencializar as associações entre as variáveis independentes desse estudo e a ocorrência de cesariana.

1. Torres JA. Análise da contribuição de um programa perinatal multifacetado para a redução da prevalência de cesarianas em um hospital privado: um subprojeto da pesquisa "Nascer no Brasil" [Tese de Doutorado]. Rio de Janeiro: Escola Nacional de Saúde Pública Sergio Arouca, Fundação Oswaldo Cruz; 2014.

2. Horton R. The power of midwifery. Lancet 2014; 384:1075-6.

3. Chaillet N, Dumont A. Evidence-based strategies for reducing cesarean section rates: a meta-analysis. Birth 2007; 34:53-64.

\section{Os autores respondem}

The authors reply

Los autores responden

http://dx.doi.org/10.1590/0102-311XC0020915

Paulo Fontoura

Freitas, Bianca

Carvalho Moreira,

Andre Luciano

Manoel, Ana Clara de

Albuquerque Botura
As colocações de Maria do Carmo Leal contribuem de maneira importante para o debate e para a busca de soluções para a questão das altas taxas de cesariana em nosso meio. Visto que o espectro de suas colocações transcendem os objetivos do estudo, gostaríamos de enfocar, em especial, duas das questões colocadas, visto serem elas pontos centrais que alicerçam nossas conclusões e que a oportunidade da presente réplica nos permite aprofundar.

Entendemos a surpresa do leitor ao se deparar com um estudo que, aparentemente, busca analisar o impacto de um parecer não referenciado pela Agência Nacional de Saúde Suplementar (ANS). Entretanto, da mesma maneira que a variável "mesmo médico" é uma proxy do modelo de assistência obstétrica no país, conforme detectado, com propriedade, por Leal, entendemos que o teor do parecer defendido pelo Conselho Federal de Medicina (CFM), independentemente de sua aprovação pela ANS, representa o pensamento de grande parte da comunidade obstétrica, fator central que instiga a presente análise.

A opinião do conselheiro federal e coordenador de comissão do CFM, que tratou do tema, ao postular que o incentivo à remuneração é essencial para favorecer a realização de partos normais e que "Esse fator, a remuneração, é sem dúvida um dos elementos essenciais de um conjunto de ações coordenadas que o CFM vem discutindo para reverter a elevada proporção de cesarianas hoje no Brasil" 1, foi na verdade o ponto de partida para o nosso estudo.

Quanto à impossibilidade de acessar com exatidão "pagamento à parte", nossos resultados mostram que a quase totalidade das mulheres que tiveram o parto pelo Sistema Único de Saúde (SUS) com o mesmo médico que realizou o pré-natal declararam não ter pago pelo parto e que a totalidade daquelas que referiram ter pago haviam realizado pré-natal privado deixando em segundo plano, ao nosso ver, a importância da variável "pagamento à parte", tanto como parte do modelo multivariado, por praticamente duplicar a informação da variável "status do parto”, quanto pela construção das conclusões finais. Subsidiando esse raciocínio, os resultados 